\title{
Changes in plasma fibronectin during acute nutritional deprivation in healthy human subjects
}

\author{
BY S. J. D. CHADWICK, A. J. W. SIM AND H. A. F. DUDLEY* \\ Academic Surgical Unit, St Mary's Hospital Medical School, London W2 IPG
}

(Received 4 March 1985 - Accepted 24 July 1985)

\footnotetext{
1. Plasma fibronectin, a glycoprotein, is an opsonin of the reticuloendothelial system.

2. In ten healthy volunteers starved for $4.5 \mathrm{~d}$, daily measurements showed a rapid reduction in plasma fibronectin, no alteration in either $\mathrm{C} 3$ or plasma transferrin and, at the end of the starvation period, an elevated serum albumin.

3. On refeeding, plasma fibronectin rapidly returned to its prestarvation level but plasma transferrin was significantly reduced and did not recover by the end of the study.

4. Changes in plasma fibronectin may be a sensitive index of nutritional status. The reduction of plasma fibronectin in short-term starvation may compromise host defence tolerance of injury and sepsis.
}

Plasma fibronectin, an $\alpha_{2}$-glycoprotein, exists as a dimer of approximately 440000 daltons, soluble at neutral $\mathrm{pH}$ and an opsonin of the reticuloendothelial system (Ruoslahti et al. 1982). Reduced levels of plasma fibronectin have been reported following uncomplicated gastrointestinal surgery (Chadwick et al. 1984), in sepsis (Rubli et al. 1983, Chadwick et al. 1984) and following burn trauma (Lanser et al. 1980). In disseminated intravascular coagulation, low concentrations of plasma fibronectin are associated with a poor prognosis (Mosher \& Williams, 1978).

Acute protein and energy deprivation is an accompaniment of uncomplicated surgical trauma. The objective of the present study was to establish the effect of short-term starvation on plasma fibronectin concentrations in healthy volunteers.

\section{EXPERIMENT AL}

\section{Subjects and methods}

Ten healthy male subjects, mean age 21.6 years (range $19-26$ years) and mean weight $76.3 \mathrm{~kg}$ (range $56 \cdot 0-109.6 \mathrm{~kg}$ ), were studied over a period of $15 \mathrm{~d}$. There were three consecutive study periods: (1) a control period of $5 \mathrm{~d}$ with subjects taking their usual diet; (2) a starvation period of $4.5 \mathrm{~d}$ when only tap- or mineral-water was allowed by mouth; (3) starting at 09.00 hours on the morning of the 10th day, a $5 \mathrm{~d}$ period of refeeding when the subjects returned to their usual diet. Blood samples and weights were taken on the 1 st and the 5 th days of the control period. During the periods of starvation and refeeding, blood was drawn and the subjects weighed each day except for the penultimate day (day 14) of the study. The subjects were weighed and blood samples taken between 07.30 and 08.30 hours. Ethics Committee approval was obtained for the study.

\section{Laboratory procedures and assay}

Plasma fibronectin and $\mathrm{C} 3$ concentrations were measured by immuno-electrophoresis using commercially available antisera (Immunodiagnostic Research Laboratory, Birmingham University and Immunostics, Seward), and plasma transferrin concentration by kinetic nephelometry (Beckmann transferrin reagent test kit). Serum albumin was measured by

$$
\text { * For reprints. }
$$


bromocresol-green dye-binding (Technicon reagents; Auto Analyzer) on the day of venepuncture. The coefficients of variation of the assays of plasma fibronectin, C3, transferrin and serum albumin using twenty identical samples of each were: $2 \cdot 1,2 \cdot 8,2 \cdot 2$ and $3 \%$ respectively.

Blood was collected in polystyrene tubes with EDTA as anticoagulant for assay of plasma fibronectin, C3 and transferrin. Within $60 \mathrm{~min}$ of venepuncture the plasma samples were stored at $-80^{\circ}$ until required for assay.

No recognized international reference samples of either plasma fibronectin or C3 exist. Therefore, the pooled plasma from ten different volunteers served as a reference sample for plasma fibronectin and C3 concentrations. Plasma fibronectin, C3 and transferrin were measured within 2 months of collection.

Ketonuria was assessed semi-quantitatively using commercially-available dip sticks (Keto-diastix; Miles Laboratories).

\section{Statistical analysis}

The results are expressed as means with their standard errors. Statistical analysis was by the Wilcoxon matched-pairs signed-ranks test.

\section{RESULTS}

The means of the two values of the body-weight, plasma fibronectin, $\mathrm{C} 3$, transferrin and serum albumin obtained during the prestarvation period have been taken as the control values. Body-weight fell during starvation in each subject. The mean percentage weight loss by the end of the starvation period (day 10) was 5.4 (SEM 0.31). Body-weight increased on refeeding, but the control weight was not regained in any subject $(98.5 \%$ (SEM $0 \cdot 26)$ ).

Urine volumes $(24 \mathrm{~h})$ were significantly reduced by the end of starvation. The mean control volume was 1474 (SEM 185) $\mathrm{ml} / 24 \mathrm{~h}$ and by the end of starvation was 834 (SEM 116) $\mathrm{ml} / 24 \mathrm{~h}(P<0.02)$. On the 2 nd day of refeeding (day 12$)$ the $24 \mathrm{~h}$ urine volumes were not significantly different from the control volumes. Ketonuria was detected in six subjects by the 2 nd day of starvation and in all subjects in increasing amounts by the end of starvation. Ketonuria was not found in any subject following the 2 nd day of refeeding.

Plasma fibronectin was significantly decreased by the 2 nd day of starvation (Table 1; day 8 ) and continued to fall. In contrast neither C3 nor plasma transferrin concentrations were different from control values by the end of starvation but the albumin concentration was significantly elevated.

After the 1st day of refeeding (day 11), plasma fibronectin, C3, transferrin and serum albumin concentrations were all less than those at the end of the starvation period (day 10). Plasma fibronectin concentration returned to the control value within $5 \mathrm{~d}$ whereas plasma transferrin concentration remained significantly reduced. Serum albumin concentration was not significantly different from the control value throughout the refeeding period. The response of $\mathrm{C} 3$ to refeeding was variable but by the end of the refeeding period was no different from the control value.

The values for plasma fibronectin, transferrin and serum albumin expressed as a percentage of the mean control value are shown in Fig. 1.

\section{DISCUSSION}

Decreased plasma fibronectin concentrations during starvation have been previously reported in obese patients (Scott et al. 1982; Howard et al. 1984). In both studies the age range was greater than thirty years. Plasma fibronectin tends to increase with age (Stathakis 


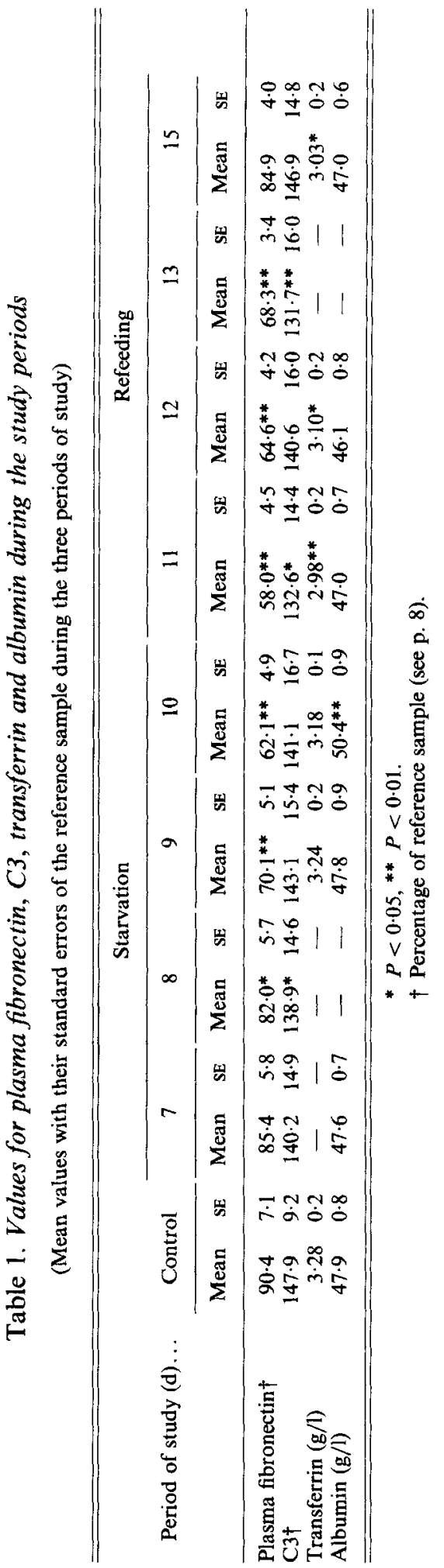




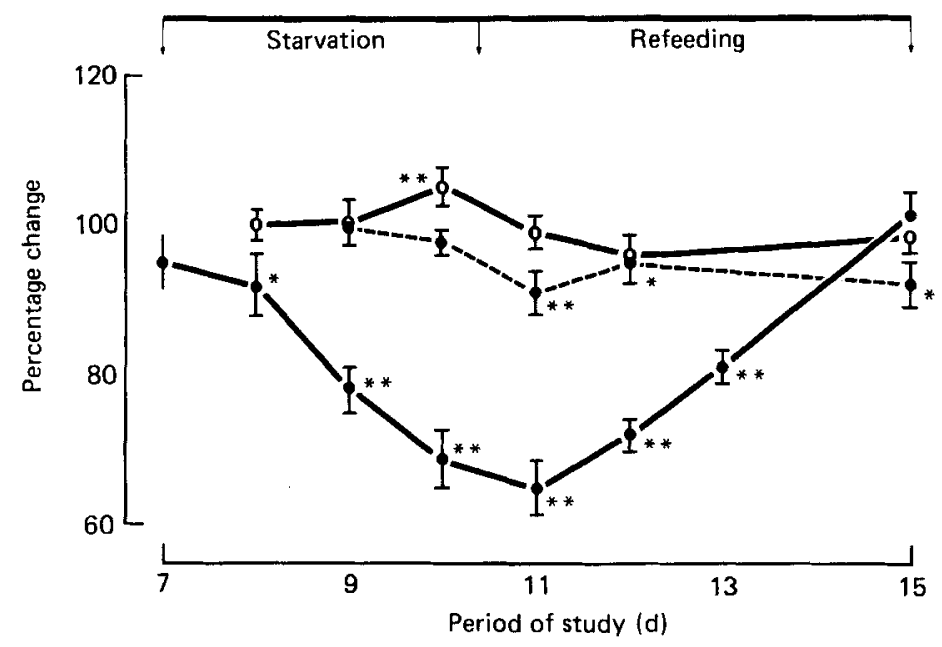

Fig. 1. Mean percentage changes, with their standard errors represented by vertical bars, of the control values of plasma fibronectin (the study. ${ }^{*} P<0.05, * * P<0.01$.

et al. 1981), the biological significance of which is unknown. To avoid this possible source of error, the present study was conducted in a group of subjects of the same age.

The elevation of serum albumin during acute starvation is well recognized (Consolazio et al. 1967; Smale et al. 1980) and has been attributed to a contraction of the volume of distribution (Maagøe, 1968), a loss of extracellular water which probably represents one major component of weight loss in early starvation (Chan et al. 1982). Plasma transferrin was not significantly altered during starvation but was reduced on the 1 st day of refeeding. Plasma fibronectin was significantly reduced by the end of the 2 nd day of starvation and continued to decrease during starvation, similarly reaching its lowest value on the 1st day of refeeding. The biological half-lives of transferrin and serum albumin are 9 and $20 \mathrm{~d}$ respectively (Awai \& Brown, 1963; Rothschild et al. 1972). The biological half-life of plasma fibronectin in rabbits is $70-75 \mathrm{~h}$ (Sherman \& Lee, 1979); in man it is unknown but is likely to be less than the $9 \mathrm{~d}$ half-life of transferrin. In the absence of trauma and sepsis, the changes of plasma fibronectin are interpreted as a result of a reduction in synthesis rate. That plasma transferrin was unaltered by the end of starvation probably indicates that the contraction of the volume of distribution masked any change in plasma concentration as a result of reduced synthesis. This mechanism might have partially obscured the reduction of plasma fibronectin but was insufficient to overcome it. During refeeding, plasma fibronectin concentration rapidly returned to the prestarvation value, unlike plasma transferrin which was significantly reduced from the control value at the end of the refeeding period.

Plasma proteins such as albumin and transferrin have been widely investigated as indices of nutritional status and markers of changes in nutritional state. These proteins, which can be broadly categorized as transport proteins, are produced principally in the liver. Although cultured liver cells are known to produce fibronectin (Ruoslahti et al. 1982), extrahepatic sites, such as vascular endothelial cells (Jaffe \& Mosher, 1978) are a major source of plasma fibronectin. Reduced plasma fibronectin concentrations have been reported in some but not all patients with fulminant hepatic failure (Gonzalez-Calvin et al. 1982) and not in patients with less-severe hepatic damage (Stathakis et al. 1981). Thus plasma fibronectin synthesis 
is unlikely to be altered by deranged liver metabolism, provided a sufficient dietary source of protein and energy is available. For this reason changes in plasma fibronectin have been suggested to be a useful nutritional marker (Brodin et al. 1982) and our results support this concept.

The opsonic properties of plasma fibronectin have been reported by Saba and colleagues (Saba \& Di Luzio, 1969; Saba, 1972; Saba \& Cho, 1980). Another important part of the humoral defence is complement. The third component, $\mathrm{C} 3$, may be activated by either the classical or alternative pathways and gives an indication of the presence of an immune response. In the present study, C3 concentration was unaffected by simple starvation, suggesting that the reduction in plasma fibronectin was not due to opsonic consumption.

In the first $3 \mathrm{~d}$ after uncomplicated gastrointestinal surgery, plasma fibronectin concentrations are reduced to approximately $70 \%$ of their preoperative value (Chadwick et al. 1984). This reduction is similar to that observed after $3 \mathrm{~d}$ of starvation, indicating that nutritional depletion may be partially responsible for this early post-traumatic decrease. Studies in rats have shown that the blood clearance of a reticuloendothelial test colloid is prolonged during starvation and that a low concentration of plasma fibronectin results in a reduction of the capacity of the reticuloendothelial system (Dillon et al. 1982). When animals with low plasma fibronectin concentrations are challenged with bacteria, they have an increased mortality (Lanser \& Saba, 1982). Repletion of plasma fibronectin with blood products rich in fibronectin improves reticuloendothelial system function in fibronectin-depleted animals (Saba, 1978; Saba \& Cho, 1980) and cardiopulmonary function and tissue oxygenation in critically-ill patients (Scovill et al. 1979). If low plasma fibronectin concentrations produce a 'gap' in host defence, the deleterious effect of short-term starvation, before and after surgery, needs to be more fully evaluated and the role of active nutritional support, to close this 'gap', should be investigated.

S. J.D.C. was supported by a grant from the locally-organized research scheme (North West Thames Regional Health Authority).

\section{REFERENCES}

Awai, M. \& Brown, E. B. (1963). Journal of Laboratory and Clinical Medicine 61, 363-396.

Brodin, B., Cederbrand, G., Larsson, J., Schildt, B., Sjodahl, R., Symreng, T. \& Wetterfors, J. (1982). Journal of Parenteral and Enteral Nutrition 6, 214-217.

Chadwick, S. J. D., Mowbray, J. F. \& Dudley, H. A. F. (1984). British Journal of Surgery 71, 718-720.

Chan, S. T. F., Johnson, A. W., Moore, M. H., Kapadia, C. R. \& Dudley, H. A. F. (1982). Human Nutrition: Clinical Nutrition 36C, 223-232.

Consolazio, C. F., Matoush, L. O., Johnson, H. L., Nelson, R. A. \& Krywicki, H. J. (1967). American Journal of Clinical Nutrition 20, 672-683.

Dillon, B. C., Saba, T. M., Cho, E. \& Lewis, E. (1982). Experimental and Molecular Pathology 36, $177-192$.

Gonzalez-Calvin, J., Scully, M. F., Sanger, Y., Fok, J., Kakkar, V. V., Hughes, R. D., Gimson, A. E. S. \& Williams, R. (1982). British Medical Journal 285, 1231-1232.

Howard, G. J., Dillon, B. C., Saba, T. M., Hofman, S. \& Cho, M. (1984). Journal of Parenteral and Enteral Nutrition 8, 237-244.

Jaffe, E. A. \& Mosher, D. F. (1978). Journal of Experimental Medicine 147, 1779-1791.

Lanser, M. E. \& Saba, T. M. (1982). Annals of Surgery 195, 340-345.

Lanser, M. E., Saba, T. M. \& Scovil, W. A. (1980). Annals of Surgery 192, $770-782$.

Maages, H. (1968). Metabolism 17, 133-138.

Mosher, D. F. \& Williams, E. M. (1978). Journal of Laboratory and Clinical Medicine 91, 729-735.

Rothschild, M. A., Oratz, M. \& Schreiber, S. S. (1972). New England Journal of Medicine 286, 748-757.

Rubli, E., Bussard, S., Frei, P., Lundsgaard-Hansen, P. \& Pappova, E. (1983). Annals of Surgery 197, 310-312.

Ruoslahti, E., Engvall, E. \& Hayman, E. G. (1982). Collagen Research 1, 95-128.

Saba, T. M. (1972). Surgery 71, 675-685.

Saba, T. M. (1978). Annals of Surgery 188, 145-152.

Saba, T. M. \& Cho, E. (1980). Advances in Shock Research 3, 251-271. 
Saba, T. M. \& Di Luzio, N. R. (1969). American Journal of Physiology 216(1), 197-205.

Scott, R. L., Sohmer, R. R. \& MacDonald, M. G. (1982). Journal of the American Medical Association 248, 2025-2027.

Scovill, W. A., Annest, S. J., Saba, T. M., Blumenstock, F. A., Newell, J. C., Stratton, H. H. \& Powers, S. R. (1979). Surgery 86, 284-293.

Sherman, L. A. \& Lee, J. (1979). Thrombosis and Haemostasis 42, 121.

Smale, B. F., Mullen, J. L., Hobbs, C. L., Buzby, G. P. \& Rosato, E. F. (1980). Journal of Surgical Research 28 , 379-388.

Stathakis, N. E., Fountas, A. \& Tsianos, E. (1981). Journal of Clinical Pathology 34, 504-508. 